\title{
O ALEITAMENTO MATERNO
}

\section{ARTIGO DE REVISÃO}

CARVALHO, Marcelo de Paula ${ }^{1}$

SANTOS, Lahis Mourão Teodora dos ${ }^{2}$

ABILIO, Cínthia ${ }^{3}$

CARVALHO, Marcelo de Paula. SANTOS, Lahis Mourão Teodora dos. ABILIO, Cínthia. O Aleitamento Materno. Revista Científica Multidisciplinar Núcleo do Conhecimento. Ano 06, Ed. 01, Vol. 03, pp. 166-177. Janeiro de 2021. ISSN: 24480959, Link de acesso: https://www.nucleodoconhecimento.com.br/saude/oaleitamento

\section{RESUMO}

O aleitamento materno é de extrema relevância no contexto de saúde e desenvolvimento do lactente. Por isso, os objetivos deste trabalho foram descrever como ocorre a apojadura e seu mecanismo fisiológico; entender os benefícios do aleitamento materno para o lactente; compreender o que é a pega correta e as consequências da má pega. Para isso, foi realizada uma revisão não sistemática da literatura a partir de artigos científicos e textos-base de livros didáticos. Desse modo, os principais resultados a serem destacados são os papéis de diversos hormônios na apojadura; a extrema importância nutricional, de desenvolvimento e imunológico do leite materno; e, por fim, a pega correta como facilitadora da amamentação.

1 Pós-graduação em Gestão e Produção Sucroalcooleira, pós-graduando em Docência Universitária, graduação em Direito, graduando em Medicina.

2 Pós-graduanda em Docência Universitária, graduação em Biomedicina, graduanda em Medicina.

${ }^{3}$ Graduação em Biologia, graduanda em Medicina. 
Palavras-Chave: aleitamento, amamentação, apojadura, benefícios, pega.

\section{INTRODUÇÃO}

Recém-nascido com 42 horas de vida apresenta temperatura de $38,3^{\circ} \mathrm{C}$, irritabilidade e icterícia com bilirrubina total de $15 \mathrm{mg} / \mathrm{dl}$ e $12 \mathrm{mg} / \mathrm{dl}$ de indireta, entrando na zona 4 de Kramer. Mãe com 32 anos, pré-natal sem intercorrências, tipo sanguíneo $O$ positivo, sorologias negativas. Parto cesárea por iteratividade, bolsa rota de 3 horas, líquido claro com grumos. Idade gestacional de 36 semanas e 6 dias. Recém-nascido com peso de nascimento de $2370 \mathrm{~g}$, tipo sanguíneo O positivo, teste de Coombs direto negativo. Apresenta perda de $9,5 \%$ em relação ao peso de nascimento e mãe queixa dificuldade para amamentar.

Esse é apenas um dos muitos casos de lactentes que entram no pronto socorro com quadros clínicos provenientes do aleitamento materno ineficaz.

Aleitamento materno é quando a criança recebe leite materno (direto da mama ou ordenhado) independentemente de receber ou não outros alimentos). A Organização Mundial da Saúde (OMS) classifica o aleitamento de acordo com a sua predominância na alimentação do lactente.

O aleitamento materno exclusivo consiste na criança receber exclusivamente leite materno, seja ele ordenhado, diretamente da mama ou leite humano de outra fonte. (WORLD HEALTH ORGANIZATION, 2020)

No aleitamento materno predominante, além do leite materno, a criança recebe água ou bebidas à base de água, como chás ou sucos de frutas. (WORLD HEALTH ORGANIZATION, 2020)

O aleitamento materno complementado acontece quando, além do leite materno, a criança recebe alimentos sólidos ou semissólidos. Sendo assim, esses alimentos sólidos ou semissólidos possuem a finalidade de apenas complementar a dieta, não substituindo o leite materno. (WORLD HEALTH ORGANIZATION, 2020) 
No aleitamento materno misto ou parcial, a criança recebe leite materno e outros tipos de leite. (WORLD HEALTH ORGANIZATION, 2020)

\section{METODOLOGIA}

Foi aplicada uma revisão não sistemática da literatura a partir de artigos científicos na língua inglesa e portuguesa. Foram utilizados os descritores "aleitamento materno", "benefícios", "apojadura", "pega". Todos os artigos respeitaram os princípios da bioética e não possuíam conflitos de interesse. Além disso, foram utilizados textosbase de livros renomados na área pediátrica, bem como na área de fisiologia médica.

\section{DISCUSSÃO/RESULTADOS}

\section{APOJADURA}

A apojadura trata-se do processo de preparação da mama para a produção de leite, no qual ocorre até cinco dias após o parto. Durante esse período, comumente as mamas encontram-se maiores e bem cheias, de maneira igual, e algumas vezes podem ficar quentes. É comum que haja um pequeno fluxo de leite, começando a descer em forma de gotas, o que é suficiente para o bebê ficar satisfeito. (LOPEZ e JUNIOR, 2017)

A maior parte do desenvolvimento estrutural da glândula mamária ocorre durante a gestação. Dito isso, sabe-se que alguns hormônios presentes no processo gestacional são responsáveis pelo crescimento e pelo desenvolvimento da glândula mamária sobre uma estreita relação entre o crescimento fetal e o desenvolvimento mamário (mamogênese). Adjunto ao parto e profundamente ligado aos eventos fisiológicos que ocasionam a expulsão do feto, inicia-se a função secretora pela a glândula (lactogênese). (LOPEZ e JUNIOR, 2017)

A Lactogênese representa o processo pelo qual a glândula mamária desenvolve a sua capacidade de produzir leite. Tal processo ocorre em duas etapas, sendo a primeira iniciada entre a $10^{\underline{a}}$ e a $22^{\underline{a}}$ semana de gestação, denominada lactogênese I. Nesta 
fase a mama está pronta para produzir leite, no entanto o faz em pequena quantidade devido à presença de altos níveis de progesterona produzido pela placenta. (LOPEZ e JUNIOR, 2017)

Após o parto, ocorre a expulsão da placenta seguida de uma queda drástica dos níveis de progesterona, enquanto, consequentemente, os níveis séricos de prolactina se elevam. Entre 24 a 48 horas a mama torna-se intumescida devido a migração de água atraída pela força hiperosmolar da lactose, com consequente dilatação dos alvéolos e ductos. Neste momento inicia-se a lactogênese II, caracterizada pela secreção mais volumosa de leite. (CHAVES et. al., 2008)

A partir desse momento, a regulação da secreção de leite passa a ser autócrina. Nesse momento, na galactopoiese, o volume de leite secretado é determinado pelo estímulo produzido pelo esvaziamento das mamas. (CHAVES et. al., 2008)

O processo de lactação inicia-se com a produção de leite realizada nos alvéolos das glândulas mamárias. Este leite produzido sai dos alvéolos e segue até o mamilo por meio dos seios lactíferos. (LOPEZ e JUNIOR, 2017)

O estrógeno e a progesterona, apesar do importante papel de desenvolver fisicamente as mamas durante o período gestacional, desempenham a função inibitória da secreção do leite. (CHAVES et. al., 2008)

Ao passo que a prolactina possui o efeito contrário, promovendo a secreção de leite. Tal hormônio é secretado por meio da hipófise anterior materna, enquanto a concentração sanguínea da gestante aumenta, de maneira progressiva, a partir da $5^{\text {a }}$ semana gestacional até o nascimento do bebê. Além disso, é responsável pelo crescimento e pela atividade secretora dos alvéolos mamários. (CHAVES et. al., 2008)

Neste sentido, a placenta também secreta somatomamotropina coriônica humana em grandes quantidades, na qual compõe-se por propriedades lactogênicas e auxilia na atividade da prolactina materna durante o período gestacional. Contudo, estes hormônios encontram-se presentes durante toda a gravidez, no entanto suas 
quantidades não se elevam, por causa da inibição ocasionada pelos altos níveis de progesterona e estrogênio. (CHAVES et. al., 2008)

No fim do trabalho de parto, os níveis de progesterona e estrogênio diminuem e consequentemente as quantidades de prolactina e lactogênio placentário aumentam, possibilitando assim o início da produção de leite. (CHAVES et. al., 2008)

O primeiro líquido secretado é denominado colostro, o qual compõe-se por quantidades iguais de proteína e lactose, contudo não há presença de gordura. Assim, até que a sucção do mamilo pelo bebê seja cessada, a prolactina continuará a produzir leite. Tal fenômeno ocorre em razão do estímulo atribuído ao hipotálamo quando o bebê faz esta sucção nos mamilos, de modo a secretar o fator liberador da prolactina, mantendo seus níveis e, por conseguinte, a produção de leite. (CHAVES et. al., 2008)

"A sucção do complexo aréolo-mamilar pelo lactente promove estímulo de neurônios sensórios locais que emitem impulsos nervosos aferentes ao hipotálamo, levando a secreção de ocitocina pela hipófise posterior" (CHAVES et. al., 2008, p.147).

Na hipófise posterior, ou neuro-hipófise, a secreção de hormônios é controlada por sinais neurais de que tem origem no hipotálamo e terminam na região hipofisária posterior. Esses sinais neurais consistem em neurônios hipotalâmicos magnocelulares, localizados nos núcleos supra ópticos (NSO) e nos núcleos paraventriculares (NPV) do hipotálamo, que projetam seus axônios para baixo, pela haste infundibular, até a pars nervosa ou lobo posterior da pituitária, um órgão neurovascular por onde os neuro-hormônios são secretados. Eles são sintetizados nos corpos celulares de neurônios magnocelulares e são transportados até a pars nervosa através dos axônios dos tratos hipotalâmicos-hipofisários. Esse mecanismo de secreção de $\mathrm{ADH}$ e ocitocina na pars nervosa é controlado pelos estímulos que são captados pelos corpos celulares e dendritos hipotalâmicos. (KOEPPEN e STANTON, 2009)

A ocitocina secretada é conduzida, por meio do sangue, até as glândulas mamárias, onde se liga a receptores específicos encontrados nas células mioepiteliais, de modo 
a promover a contração da mesma e a expulsão do leite dos alvéolos aos ductos e seios subareolares. Tal processo é denominado reflexo de ejeção do leite. A secreção de ocitocina é inibida por catecolaminas, substâncias liberadas em situações de estresse ou dor. Há evidência de que a prevenção ao estresse psíquico ou à dor, assim como o tratamento de situações que exponham gestante a tais situações são fatores fundamentais para o sucesso da amamentação. (CHAVES et. al., 2008)

A ocitocina consiste num hormônio que potencializa as contrações uterinas, de modo a lhes tornar fortes e coordenadas, até o fim do parto. No início do período gestacional, verifica-se a inexistência de receptores no útero para a ocitocina. Ao passo que, no decorrer da gravidez, os mesmos vão aparecendo progressivamente. Quando a ligação entre a ocitocina e estes receptores ocorre, ocasiona-se a contração do músculo liso uterino, assim como a estimulação da produção de prostaglandinas, pelo útero, que irá ativar o músculo liso uterino. Deste modo, entende-se que o parto é dependente da secreção da ocitocina e da produção das prostaglandinas, visto que sem elas, o colo do útero não terá uma dilatação adequada e consequentemente, o parto não irá ocorrer normalmente. (CHAVES et. al., 2008)

Neste sentido, durante todo o período gestacional, a progesterona mantém-se em níveis elevados, de modo a inibir o músculo liso uterino, bloqueando sua resposta à ocitocina e às prostaglandinas. Enquanto o estrogênio aumenta o grau de contratilidade uterina. No fim da gestação, em sua última etapa, verifica-se que o nível do estrogênio em relação a progesterona tende a aumentar mais, possibilitando ao útero uma contratilidade maior. Contudo, a relaxina aumenta a quantidade de receptores para a ocitocina, assim como produz um rápido amolecimento das articulações pélvicas e das suas cápsulas articulares, proporcionando-lhes a flexibilidade necessária para o parto. (CHAVES et. al., 2008)

O Inibidor de Feedback da Lactação (IFL) "é uma glicoproteína de baixo peso molecular sintetizada pela glândula mamária e secretada para o leite. Esta substância bloqueia de forma reversível a síntese de proteínas pelas células mamárias". O IFL se acumula nos alvéolos mamários em meio as mamadas, impedindo a secreção proteica. Quando a mama esvazia-se, ligeiramente o bloqueio acaba e as células 
mamárias reiniciam o processo de produção de proteína e lactose, responsáveis pelo volume do leite. Dito isso, a função do IFL parece elucidar o efeito do esvaziamento mamário na produção láctea (CHAVES et. al., 2008, p.148).

Logo após o nascimento, pequeno volume de leite é produzido, 37 a $169 \mathrm{ml}$ de colostro durante as primeiras $48 \mathrm{hs}$. A partir do $5^{\circ}$ dia após o parto, a mulher é capaz de produzir de 500 a $750 \mathrm{ml}$ de leite por dia, e depois do $14^{\circ}$ dia, de 700 a $1000 \mathrm{ml}$ por dia. Deste modo, mães de gêmeos ou trigêmeos podem produzir 2 litros ou mais de leite diariamente, evidenciando que os mecanismos fisiológicos são capazes de se adaptarem à produção de leite de acordo com as necessidades nutricionais dos lactentes. Dito isso, o volume do leite produzido pela mãe pode ser regulado pelos lactentes através dos seguintes mecanismos: frequência das mamadas: um aumento na frequência das mamadas está associado ao aumento do volume de leite secretado. (LOPEZ e JUNIOR, 2017)

O esvaziamento mamário remove o IFL possibilitando maior secreção de leite. Assim, faz-se necessário lembrar que o esvaziamento mamário depende crucialmente da pega do complexo aréolo-mamilar pelo lactente de forma adequada. Tal procedimento também evita o trauma mamilar e consequente dor, sintoma relacionado à inibição do reflexo de ejeção. (CHAVES et. al., 2008)

\section{BENEFÍCIOS DO LEITE MATERNO PARA O LACTENTE}

O leite materno apresenta diversos benefícios para o lactente, por isso que um aleitamento deficiente promove uma infinidade de problemáticas para o recémnascido, que deve fazer uma dieta exclusiva de leite materno até os seis meses de idade.

De modo geral, o leite materno nutre e protege o recém-nascido, promovendo o seu desenvolvimento físico, psíquico e emocional; reduz alergias, chances de desenvolvimento de asma em crianças sem histórico familiar e doenças crônicas. Ademais, diminui as chances de desenvolvimento de obesidade e diabete tipo II, promove pressões sistólica e diastólica mais baixas e níveis menores de colesterol 
total. Além disso, reduz consideravelmente a mortalidade infantil ( 0 a 12 meses) e neonatal (0 a 28 dias). (JONES et. al., 2003; KHAN et. al., 2015; LAMBERTI et. al., 2011; IP, et. al., 2009; GDALEVICH, et. al., 2001; HORTA e VICTORA, 2013)

Um importante ponto positivo é a redução da incidência e gravidade da diarreia infantil. O leite materno contém oligossacarídeos (mais de 130 compostos), que previnem a ligação da bactéria na superfície mucosa e protegem contra enterotoxinas no intestino, ligando-se à bactéria. Além disso, contém o fator bífido, que favorece o crescimento do Lactobacillus bifidus na criança, uma bactéria saprófita que acidifica as fezes, dificultando a instalação de bactérias que causam diarreia, como Escherichia coli. (LOPEZ e JUNIOR, 2017)

É possível destacar, ainda, a redução da morbidade por infecções respiratórias e otite média aguda em recém-nascidos. (LAMBERTI et. al., 2011) O leite materno possui leucócitos e diversos anticorpos, especialmente o $\lg A$, que impede a ligação de bactérias e vírus às membranas mucosas. (LOPEZ e JUNIOR, 2017; LEVINSON, 2016) Contém, ainda, lisozima e lactoferrina, que atuam sobre bactérias, vírus e fungos. (LOPEZ e JUNIOR, 2017)

A defensina do tipo beta 2 também tem uma importante função - ela é produzida na glândula mamária e secretada no leite materno, daí atribui-se uma importante função imunológica do leite materno. Esses peptídeos contêm cerca de 29 a 34 aminoácidos. As defensinas têm toxicidade direta aos microrganismos - como bactérias, fungos e vírus envelopados -, bem como ativam células envolvidas na resposta inflamatória aos microrganismos. Essa toxicidade direta da defensina aos microrganismos se deve à sua capacidade de se inserir e desorganizar as funções das membranas microbianas. (BARICELLI et. al., 2015)

O melhor desenvolvimento cognitivo e de inteligência também pode ser atrelado à amamentação. As gorduras representam o componente mais variável do leite materno, sendo as responsáveis por suprir até $50 \%$ das necessidades energéticas da criança pequena. Os ácidos graxos poli-insaturados de cadeia longa são essenciais no desenvolvimento cognitivo e visual, e na mielinização dos neurônios. (VICTORA 
et. al., 2015) Ademais, possui uma concentração elevada de cistina e taurina, aminoácidos importantes no desenvolvimento do Sistema Nervoso Central. (SILVA et. al., 2007)

A cavidade bucal também é beneficiada pelo aleitamento. A interrupção precoce da amamentação relacionada ao exercício da retirada de leite do seio da mãe realizada pela criança, pode determinar a ruptura do desenvolvimento motor-oral harmônico, de modo a prejudicar o alinhamento adequado dos dentes e as funções de mastigação, deglutição, respiração e fala. (NEIVA et. al., 2003)

A amamentação promove o vínculo afetivo entre mãe e filho. $O$ transtorno puerperal pode provocar, na mãe, a dificuldade em amamentar e criar esse vínculo. (LOPEZ e JUNIOR, 2017)

A icterícia apresenta-se como um dos problemas mais frequentes no período neonatal e compreende-se pela expressão clínica hiperbilirrubinemia. A Hiperbilirrubinemia é caracterizada pela concentração sérica de bilirrubina indireta $(\mathrm{BI})$ maior que 1,3 $1,5 \mathrm{mg} / \mathrm{dL}$ ou de bilirrubina direta $(\mathrm{BD})$ maior que $1,5 \mathrm{mg} / \mathrm{dL}$, desde que esta represente mais que $10 \%$ do valor de bilirrubina total (BT). Tal icterícia costuma acontecer na primeira semana de vida associada a perda de peso no terceiro dia de vida $5 \%$ maior do que dos outros recém-nascidos em aleitamento materno, em razão da ingestão inadequada do leite materno, ocasionando, portanto, o aumento da circulação ênterohepática de bilirrubina e, por conseguinte, um maior aporte desta à circulação sanguínea. Este fenômeno pode ocorrer tanto por uma dificuldade na sucção do bebê, como pouca oferta do leite pela mãe, vale ressaltar que, esse contexto leva tanto a perda de peso quanto à desidratação do lactente. (LOPEZ e JUNIOR, 2017)

\section{A IMPORTÂNCIA DA PEGA CORRETA}

A má pega interfere na dinâmica de sucção e extração de leite, dificultando o esvaziamento da mama, com consequente diminuição da produção de leite e ganho de peso insuficiente do bebê, apesar de, muitas vezes, ele permanecer longo tempo no peito. (LOPEZ e JUNIOR, 2017) 
O recém-nascido pode conseguir obter o leite anterior, mesmo com a má pega. Contudo, ele tem dificuldade de obter o leite posterior, que é mais nutritivo e rico em gorduras. Além disso, uma má pega pode gerar traumas mamilares, podendo interromper a amamentação devido à dor, ingurgitamento ou ductos lactíferos bloqueados. (LOPEZ e JUNIOR, 2017)

Além da pega correta, para a prevenção de traumas mamilares recomenda-se manter os mamilos secos e evitar protetores de mamilos. Além disso, no momento da mamada, é recomendado ordenhar um pouco de leite para que a aréola fique mais macia (facilitando a pega), quando estiver tensa e ingurgitada e na interrupção da mamada, introduzir o dedo mínimo na boca do bebê pela comissura labial, para romper o vedamento labial. (LOPEZ e JUNIOR, 2017)

Para o ingurgitamento mamário e ductos mamários bloqueados recomenda-se manter a amamentação, amamentar com mais frequência e em livre demanda, ordenhar o excesso de leite por meio de ordenha manual ou mecânica, esvaziamento regular da mama melhora o fluxo venoso e linfático e mantém a produção de leite, massagear com movimentos circulares toda a mama e particularmente as regiões com ingurgitamento mais, ordenhar um pouco de leite antes da mamada (se a aréola estiver tensa), manter medidas de suporte. Ademais, utilizar compressas frias nas mamas, nos intervalos das mamadas. Se necessário, com o agravamento ou não melhora do quadro, recomenda-se o uso de analgésicos sistêmicos. O ibuprofeno é recomendado, já que tem efeito analgésico e anti-inflamatório; como alternativa, podese prescrever o paracetamol. (LOPEZ e JUNIOR, 2017)

Alguns sinais são indicativos de pega incorreta, são eles: bochechas do bebê encovadas a cada sucção; ruídos da língua; mama apresentando estar esticada ou deformada durante a mamada; mamilos com estrias vermelhas; mamilos com áreas esbranquiçadas ou achatadas quando o bebê solta a mama; dor durante a amamentação. (LOPEZ e JUNIOR, 2017)

Para a obtenção de uma pega correta deve-se assegurar que a aréola fique um pouco mais visível acima da boca do bebê; manter a boca do recém-nascido bem aberta e 
com o lábio inferior virado para fora; o queixo do lactente deve estar tocando a mama. (LOPEZ e JUNIOR, 2017)

A pega correta só é feita se o posicionamento da mãe e bebê estiver correto. O rosto do lactente deve estar de frente para a mama, com nariz em oposição ao mamilo; o corpo do recém-nascido deve estar próximo ao da mãe, estando com cabeça e tronco alinhados. Para isso, o bebê deve estar bem apoiado. (LOPEZ e JUNIOR, 2017)

Além disso, não recomenda-se o uso de chupetas, uma vez que os músculos usados para a sucção da mama são diferentes dos que são usados na sucção da chupeta. Com isso, o lactente acaba "confundindo os bicos" e não consegue realizar uma sucção adequada do leite, prejudicando a pega. (LOPEZ e JUNIOR, 2017)

Uma posição moderna de amamentação chamada de "laid-back breast-feeding" vem ganhando destaque. A mãe deve estar em posição semi deitada, relaxada, com cabeça e pescoço bem apoiados. O bebê fica em cima da mãe, em posição longitudinal ou oblíqua, não havendo necessidade de apoio suporte, já que o recémnascido já fica naturalmente apoiado na mãe. A mãe pode ficar com as mãos livres. Essa posição estimula os reflexos neonatais primitivos do bebê (rastejamento, acomodação, preensão palmar e plantar, flexão das mãos, dos pés e dos dedos, mãos na boca, abertura da boca, lambida, sucção e deglutição). (COLSON, 2012)

\section{CONCLUSÃO}

O aleitamento materno é fruto de um complexo mecanismo fisiológico que ocorre desde a gestação. Os hormônios envolvidos nesse processo são a ocitocina, progesterona, somatomamotropina coriônica, prolactina, lactogênio placentário e inibidor de feedback de lactação.

O leite materno apresenta diversas propriedades que ajudam na nutrição e desenvolvimento do lactente. Além disso, possui função imunológica e cognitiva. Portanto, para a manutenção da homeostase do recém-nascido torna-se imprescindível. 
A pega correta é fundamental para uma boa amamentação. Esse mecanismo propicia a eficiência do aleitamento materno, uma vez que estimula corretamente a mama da mãe a secretar leite, além de favorecer a sucção do recém-nascido. Uma má pega gera problemas para a mãe e para o lactente. Para a mãe, pode gerar traumas mamilares e, para o bebê, pode gerar problemas de nutrição, desidratação e icterícia.

Sendo assim, torna-se evidente a importância do aleitamento materno. Portanto, deve ser feita a orientação correta para a mãe desde o momento em que se encontra gestante, destacando a importância da amamentação e como é feita a pega correta.

\section{REFERÊNCIAS BIBLIOGRÁFICAS}

BARICELLI, Joanna et al. B-defensina 2 no leite materno mostra uma ampla atividade antimicrobiana contra bactérias patogênicas. J. Pediatr. (Rio J.), Porto Alegre, v. 91, n. 1, p. 36-43, 2015.

CHAVES, R. G. et. al. Uso de galactagogos na prática clínica para o manejo do aleitamento materno. Revista Médica de Minas Gerais, 2008; 18:146-53.

COLSON, S. The laid-back breastfeeding revolution. Midwifery Today, 2012. Disponível em: www.biologicalnurturing.com/assets/MT101BioNurtpdf.pdf. Acesso: 18 out. 2020.

GDALEVICH, M.; et. al. Breast-feeding and the onset of atopic dermatitis in childhood: a systematic review and meta -analysis of prospective studies. J Am Acad Dermatol 2001; 45(4):520-7.

HORTA, B. L.; VICTORA, C. G. Long-term effects of breastfeeding. A systematic review. Geneva: World Health Organization, 2013.

JONES, G.; et. al. How many child deaths can we prevent this year? Lancet 2003; 362:65-71. 
KHAN, J.; et. al. Timing of breastfeeding initiation and exclusivity of breastfeeding during the first month of life: effects on neonatal mortality and morbidity - a systematic review and meta-analysis. Matern Child Health J 2015; 19:464-79.

KOEPPEN, B.M.; STANTON, B.A. Berne \& Levy: Fisiologia. 6. ed. Rio de Janeiro: Elsevier, 2009.

LAMBERTI, L. M.; et. al. Breastfeeding and the risk for diarrhea morbidity and mortality. BMC Public Health 2011; 11(Supp/3):S15.

IP, S.; et. al. A summary of the Agency for Healthcare Research and Quality's evidence report on breastfeeding in developed countries. Breastfeed Med 2009; 4 Suppl 1:S17-30.

LEVINSON, W. Microbiologia Médica e Imunologia. Amgh Editora, 13ª Ed. 2016.

LOPEZ, F. A.; JUNIOR, D. C. Tratado de Pediatria - Sociedade Brasileira de Pediatria. Manole, 2017.

NEIVA, F. C. B.; et. al. Desmame precoce: implicações para o desenvolvimento motor-oral. J Pediatr 2003; 79:7-12.

SILVA, Roberta Claro da.; et al. Composição centesimal do leite humano e caracterização das propriedades físico-químicas de sua gordura. Quím. Nova, São Paulo, v. 30, n. 7, p. 1535-1538, 2007.

VICTORA, C. G.; et. al. Association between breastfeeding and intelligence, educational attainment, and income at 30 years of age: a prospective birth cohort study from Brazil. Lancet Glob Health 2015; 3(4):e199-205.

WORLD HEALTH ORGANIZATION. Indicators for assessing infant and child feeding practices. Disponível em: https://www.who.int/teams/maternal-newbornchild-adolescent-health-and-ageing. Acesso: 18 out. 2020. 
Enviado: Dezembro, 2020.

Aprovado: Janeiro, 2021. 